\title{
Surface Modification Effect of Volcanic Ash Particles Using Silane Coupling Agent on Mechanical Properties of Polyphenylene Sulfide Composites
}

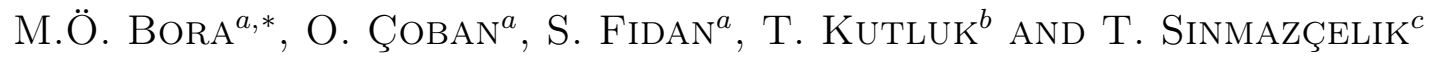 \\ ${ }^{a}$ Kocaeli University, Faculty of Aeronautics and Astronautics, 41285, Kartepe-Kocaeli, Turkey \\ ${ }^{b}$ Kocaeli University, Department of Chemical Engineering, 41380, Umuttepe-Kocaeli, Turkey \\ ${ }^{c}$ Kocaeli University, Department of Mechanical Engineering, 41380, Umuttepe-Kocaeli, Turkey
}

\begin{abstract}
The surface treatment of volcanic ash particles with various concentrations $(1-3-5 \%(\mathrm{v} / \mathrm{v}))$ silane coupling agent (3-aminopropyltriethoxysilane (3-APTS)) having organic functional group was conducted. After surface treatment, polyphenylene sulfide (PPS) composite samples containing surface treated volcanic ash particles at two concentrations (10 and $15 \mathrm{wt} \%$ ) were manufactured by twin screw extruder and injection molding machine. This study investigated the effect of surface modification on mechanical properties of two different concentrated volcanic ash/PPS composites. All tests were performed using a Shimadzu AG-X Universal Tester. Tensile and three point bending tests were carried out at a crosshead speed of $1 \mathrm{~mm} / \mathrm{min}$ and $2 \mathrm{~mm} / \mathrm{min}$ according to ISO $527-2$ and ASTM D790 standards, respectively. During the experiments, the relation between the mechanical properties and surface treatment concentrations of silane agent on volcanic ash/PPS composites was determined as a function of tensile strength and modulus, flexural strength and modulus. Moreover, fracture surface morphologies of volcanic ash/PPS composite samples were observed by using a scanning electron microscopy.
\end{abstract}

DOI: 10.12693/APhysPolA.129.495

PACS/topics: 81.05.Qk

\section{Introduction}

Polyphenylene sulfide is an attractive matrix material because of its excellent mechanical properties, high temperature durability, chemical resistance, and easy processing [1]. PPS is a semicrystalline thermoplastic engineering polymer, which has become a key point in research due to its excellent high temperature stability, good solvent resistance, inherent flame resistance, and so on. The outstanding characteristics of PPS made it widely applied in general and specialty fields, including electronic, automotive and aerospace, therefore, the mechanical property of PPS is required for application purpose [2]. The incorporation of inorganic fillers in polymers is a widely used practice in industry to obtain new plastics with better properties at relatively low cost [3]. Volcanic ashes (VA) are vitreous pyroclastic materials produced by violent eruptive volcanic action [4]. VA, known as mesoporous material, usually has high specific surface area, significant porosity, and an appropriate pore structure, which enhances their ability to control the humidity in the environment.

The main component of the weathered VA soil is allophane. With specific properties, allophane can be used to produce porous ceramics that are low-cost with welldefined porosity, low density, and high thermal stability [5]. Poor interfacial adhesion between inorganic fillers and polymers is frequently observed. Hence, different

*corresponding author; e-mail: ozgur_bora@yahoo.com additives such as coupling agents able to react with the filler are often added in the formulations [3]. They have reactive groups compatible with the chemical nature of the polymer and the filler $[6,7]$.

One of the most commonly used groups of coupling agents are the silanes [8] with two kinds of reactive groups (inorganic and organic) in a single molecule [3]. A chemical reaction between the filler functional groups (such as $\mathrm{OH}$ ) and the alkoxy groups of silane is expected to occur during the treatment of the filler, creating a silanefunctionalized surface. A protective layer able to prevent the agglomeration of the filler particles is also created by silane treatment [3]. In addition, in many applications of filler reinforced polymers, mechanical properties such as tensile and flexural strengths are very important and, particularly, the optimization of the materials' mechanical properties is often required. For this purpose, in this study, the effect of surface treatment volume fractions on mechanical properties of VA/PPS composites was determined. Beside this, fracture surface morphologies of VA/PPS composite samples were observed by using a scanning electron microscopy (SEM).

\section{Materials and methods}

2.1. Materials and surface modification of inorganic VA particles

Polyphenylene sulfide (PPS) utilized as the matrix resin for the microcompounding and injection molding was Fortron 1200L1 provided by Ticona Co [9]. The Fortron 1200L1 is an unfilled grade for extrusion applications and has a density of $1.34 \mathrm{~g} / \mathrm{cm}^{3}$. VA samples were taken from Guneydag tuff ring, which is located $13 \mathrm{~km}$ southwest of Nevsehir/Turkey. VA samples 
from Guneydag tuff ring were estimated as aphyric because of lack of minerals in the VA. The Guneydag tuff ring ash samples comprise only volcanic glass. According to the energy dispersive spectrometer analysis, glass was determined as rhyolite (silica rich composition). Major element analysis from whole samples gave the same results indicating the rhyolitic composition for samples. Nearly all vitric grains are angular and highly vesicular. A sum of VA whose particle size was $71 \mu \mathrm{m}$ was added in methanol at overnight by stirring $200 \mathrm{rpm}$ to rip off from miriness and then washed with distilled water when $\mathrm{pH}$ reaches up to 7.0. Methanol and sodium hydroxide were purchased from Merck. All other chemicals and 3-aminopropyltriethoxysilane (3-APTS) were used analytical grade and purchased from Sigma Chem. Ltd (USA) and Merck (Germany). Afterwards $50 \mathrm{ml}$ of $5 \mathrm{~N}$ $\mathrm{NaOH}$ solution was prepared for cleaning the VA particles. The mixture was kept in water bath more than half an hour at $100{ }^{\circ} \mathrm{C}$. VA turbid compositions were removed by filtration and shaked in 1 litre of distilled water for detaching the $\mathrm{NaOH}$ on the surface of VA. Pure VA turbid compositions were dried at $110^{\circ} \mathrm{C}$ in oven during $24 \mathrm{~h}$. Powdered dry VA particles were mixed in recently prepared 3 -APTS $1-3-5 \%(\mathrm{v} / \mathrm{v})$ in distilled water. The mixture was shaken at $75^{\circ} \mathrm{C}$ in $200 \mathrm{rpm}$ on magnetic stirrer. At last, VA turbid compositions were filtred with watman filter paper in filtering flask to obtain the silanized VA particles. All the experimental steps were implemented for alkaline VA particles. Different silanization procedures with various silane coupling agents were widely explained in literature [10].

\subsection{Sample preparation with microcompounding and injection molding}

VA/PPS composite samples containing surface treated VA particles at two different concentrations (10 and $15 \mathrm{wt} \%$ ) were manufactured by twin screw extruder and injection molding machine. For melt compounding, DSM Xplore ${ }^{\circledR} 15 \mathrm{ml}$ microcompounder (Geleen, The Netherlands) with a maximum processing temperature of $400^{\circ} \mathrm{C}$ and a screw speed of $250 \mathrm{rpm}$ was used [11]. It has co-rotating conical twin-screw and its processing temperature can be controlled with 6 heating zones. DSM Xplore ${ }^{\circledR} 12 \mathrm{ml}$ injection molding machine (Geleen, The Netherlands) was used for injection molding of compounded melt. Its maximum processing and mold temperatures are $400^{\circ} \mathrm{C}$ and $200^{\circ} \mathrm{C}$, respectively. Also its maximum pressure capacity is 16 bar. After that, materials (granule PPS and surface treated VA particles) were weighted in the proportions needed and then melt compounded in the microcompounder. The melted material was then transferred into the injection molding machines' gun. Eventually the extruded material in the gun was injected into the standard sample molds such as ISO 527-2-5A (tensile samples) and ASTM D790 (flexural samples). In this study, optimum process parameters of surface treated VA/PPS composites were given for tensile and flexural tests in Table I.
VA/PPS composites processing parameters.

\begin{tabular}{c|c|c|c|c}
\hline \hline $\begin{array}{c}\text { Process } \\
\text { wachines }\end{array}$ & Process parameters & Unit & $\begin{array}{c}\text { Tensile } \\
\text { tests }\end{array}$ & $\begin{array}{c}\text { Flexural } \\
\text { tests }\end{array}$ \\
\hline $\begin{array}{c}\text { microcompounder } \\
\text { microcompounder }\end{array}$ & barrel temperature & {$\left[{ }^{\circ} \mathrm{C}\right]$} & 340 & 340 \\
microcompounder & compounding round & {$[\mathrm{rpm}]$} & 100 & 100 \\
injection molding & mold temperature & {$[\mathrm{min}]$} & 5 & 5 \\
injection molding & injection pressure & 150 & 150 \\
injection molding & holding pressure & 12 & 12 \\
injection molding & holding time & {$[\mathrm{b}]$} & 12 & 8 \\
\cline { 2 - 4 } & & 10 & 15
\end{tabular}

\subsection{Mechanical tests and SEM}

All tests were performed using a Shimadzu AG-X Universal Tester. A load cell with a maximum loading of $10 \mathrm{kN}$ was used. Tensile tests were carried out at a crosshead speed of $1 \mathrm{~mm} / \mathrm{min}$ according to ISO 527-2. For each experiment at least 5 samples were tested and the average tensile strength and modulus were reported with standard deviations. Three point bending tests were conducted on VA/PPS composite samples having dimensions of $80 \times 10 \times 4 \mathrm{~mm}^{3}$ using three point bending setup with span value of $64 \mathrm{~mm}$ between the two supports. Quasi-static loading with crosshead velocity of $2 \mathrm{~mm} / \mathrm{min}$ was carried out according to ASTM D790 standard. Five replicates were done for each sample group and the average values of flexural strength and modulus were reported with standard deviations. To characterize the morphology of fractured surfaces of surface treated VA particle reinforced PPS composites, the surfaces of mechanically tested samples were examined by using a field emission SEM (Vega3 SB Easy Probe).

\section{Results and discussion}

Figure 1 shows the influence of 3-APTS coupling silane agent on the mechanical properties of 10-15 wt\% alkaline VA/PPS composites. From Fig. 1a and c, it was clearly determined that the elasticity modulus and flexural modulus of both 10 and 15 wt\% alkaline VA/PPS composites were increased due to treatment of alkaline VA particles with all vol. $\%(1 \%, 3 \%$ and 5\%) 3-APTS coupling silane agent. At 5 vol. $\%$ of 3 -APTS, the elasticity and flexural modulus values of $10-15 \mathrm{wt} \%$ alkaline VA/PPS composites were increased approximately by $7 \%$ and $5 \%, 7 \%$ and $7 \%$, respectively. In addition, Fig. $1 \mathrm{~b}$ and $\mathrm{d}$ showed that the maximum tensile and flexural strength values of both 10 and 15 wt $\%$ alkaline VA/PPS composites were obtained with 3 vol.\% 3-APTS coupling silane agent. At 3 vol.\% silane treatment, consistence between alkaline VA particles and PPS matrix was improved. By this way, interface of particle/matrix was well developed. At 3 vol.\% of 3-APTS, the tensile and flexural strength values of $10-15 \mathrm{wt} \%$ alkaline VA/PPS composites were increased approximately by $3 \%$ and $2 \%$, $2.5 \%$ and $2 \%$, respectively. At higher silane concentrations ( 5 vol. $\%$ ), values of tensile and flexural strengths were decreased rapidly due to unreacted free silane agents in the composite samples. 

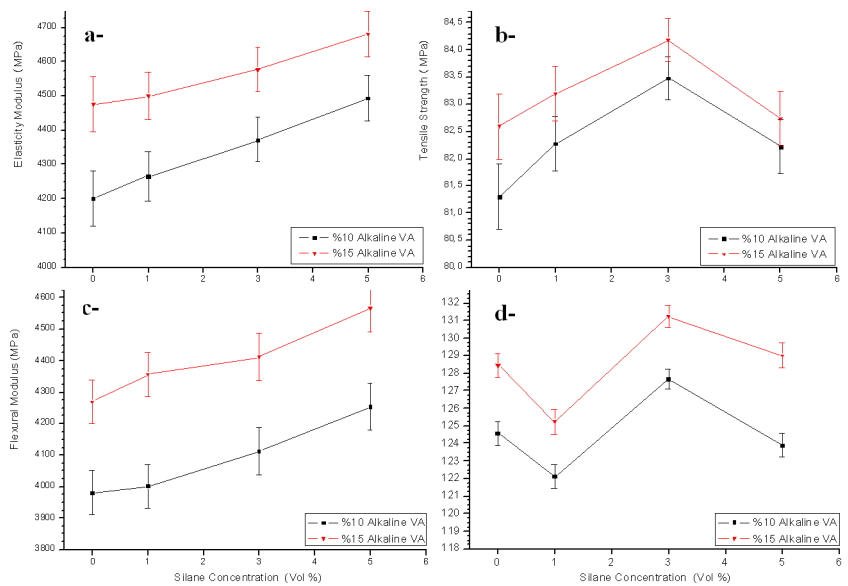

Fig. 1. The influence of 3-APTS coupling silane agent on the mechanical properties of $10-15 \mathrm{wt} \%$ alkaline VA/PPS composites (a) elasticity modulus, (b) tensile strength, (c) flexural modulus, (d) flexural strength.

Figure 2 illustrates the fractured surfaces of $15 \mathrm{wt} \%$ alkaline VA/PPS composites with various concentrations of 3-APTS coupling silane agent after mechanical tests. Fractured surfaces of silane treated $10 \mathrm{wt} \%$ alkaline VA/PPS composites were similar to $15 \mathrm{wt} \%$ alkaline VA/PPS composites' fractured surfaces. Therefore, in this work only fractured surfaces of $15 \mathrm{wt} \%$ alkaline $\mathrm{VA} / \mathrm{PPS}$ composites were given. After tensile tests, from Fig. 2a-c it was determined that PPS matrix covered almost all alkaline VA particles at 3 vol.\% 3-APTS. It was demonstrated that VA particles/matrix interfaces were strong. On the other hand, at 1 and 5 vol.\%, some damage mechanisms were observed as weak interfaces and too much visible VA particles. After three-point bending tests, from Fig. 2d-f the fractured surfaces of samples were similar to tensile test samples. Strong interface regions were obtained at 3 vol.\% 3-APTS. Beside this, different damage mechanisms were observed as minor cracks, tear damages and alkaline VA particles pullout due to nature of bending.

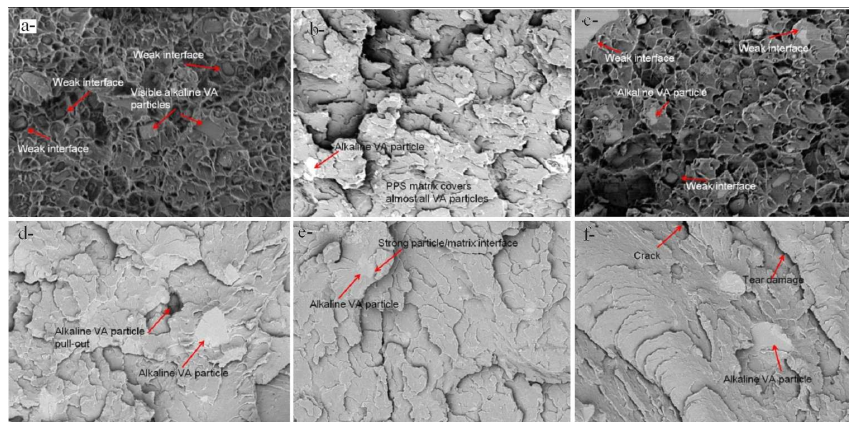

Fig. 2. Fracture surface analysis of $15 \mathrm{wt} \%$ alkaline VA/PPS composites with various concentrations of 3APTS coupling silane agent, (a)-(c) tensile test samples and $(\mathrm{d})-(\mathrm{f})$ three point bending test samples.

\section{Conclusions}

In this study, the effect of surface treatment volume fractions on mechanical properties of VA/PPS composites was determined. Maximum tensile and flexural strength values of both 10 and $15 \mathrm{wt} \%$ alkaline VA/PPS composites were obtained with 3 vol. $\% 3$-APTS coupling silane agent. Beside this, fracture surface morphologies of VA/PPS composite samples were observed by using SEM. After tensile and three point bending tests, strong interface regions were obtained at 3 vol.\% 3 -APTS. On the other hand, at 1 and 5 vol. $\%$ of 3 -APTS, some damage mechanisms were observed as weak interfaces, too much visible VA particles, minor cracks, tear damages and alkaline VA particles pull-out.

\section{Acknowledgments}

This work is supported by TUBITAK, "The Scientific and Technological Research Supporting Program 1001" under contract number of 213M563.

\section{References}

[1] C.J. Schwartz, S. Bahadur, Wear 237, 261 (2000).

[2] Y. Yang, H. Duan, S. Zhang, P. Niu, G. Zhang, S. Long, X. Wang, J. Yang, Compos. Sci. Technol. 75, 28 (2013).

[3] S.G. Pardo, C. Bernal, M.J. Abad, J. Cano, L.B. Losada, Compos. Interface 16, 97 (2009).

[4] P.N. Lemougna, U.F.C. Melo, M.P. Delplancke, H. Rahier, Ceram. Int. 40, 811 (2014).

[5] E. Avcu, O. Çoban, M.Ö. Bora, S. Fidan, T. Sinmazçelik, O. Ersoy, Polym. Compos. 35, 1826 (2014).

[6] J. Pionteck, V.B. Sadhu, L. Jakisch, P. Pötschke, L. Häubler, A. Janke, Polymer 46, 6563 (2005).

[7] S. Thongsang, N. Sombatsompop, Polym. Compos. 27, 30 (2005).

[8] D.S. Chaudhary, M.C. Jollands, F. Cser, Adv. Polym. Tech. 23, 147 (2004).

[9] Ticona, 2014. Information on http://tools.ticona. $\mathrm{com} /$ tools/mcbasei/product-tools.php?sPolymer= $\{\&\}$ sProduct $=,(10.03 .2015)$.

[10] A.G.S. Prado, C. Airoldi, Pest. Manag. Sci. 56, 419 (2000).

[11] DSM, 2014. Information on http://www. xplore-together.com/15ml_compounder.htm., (12.03.2015). 